NOTICE: This is the version of the work titled Coiled Tube Turbodrilling: A proposed technology to optimise drilling deep hard rocks for mineral exploration by Amir Mokaramian, Vamegh Rasouli and Gary Cavanough, in which changes resulting from the publishing process, such as peer review, editing, corrections, structural formatting, and other quality control mechanisms may not be reflected in this document. Changes may have been made to this work since it was submitted for publication. 


\title{
Coiled Tube Turbodrilling: A proposed technology to optimise drilling deep hard rocks for mineral exploration
}

\begin{abstract}
The need to drill deep boreholes more efficiently for mineral exploration has raised the attention to investigate the feasibility of recent drilling technologies for such applications. The two principal methods of reverse circulation (RC) and diamond core drilling are usually used in combination by mine operators are subjected to certain limitations and inefficiencies. Considering that delivering large volume of reliable samples from deep zones to the surface in shortest possible time is of paramount importance in mineral exploration, then drilling small size holes as fast as possible and delivering the small chip samples to the surface would be a good alternative with several advantages over conventional drilling methods. As a result, the Coiled Tube (CT) Turbodrilling technology is proposed here followed by presenting detailed calculations for the system required power and hydraulics and also bottom hole assembly selection suitable for hard rocks mineral exploration applications.
\end{abstract}

\section{Keywords}

Mineral exploration, hard rocks drilling, Exploration drilling, Coiled tubing, Turbodrilling, Drilling power and hydraulics.

\section{Introduction}

Drilling deep wells is not a new practice and has been attempted in oil and gas and mining applications for different purposes. The deepest scientific research well drilled is the "SG-3" well in Russia which reached a depth of 12,263 m in 1989 (Fuchs et al., 1990). The Deepest mining exploration borehole drilled in South Africa was 5,520 m using an aluminium rod (Fletcher, 1992). The gold mining industry now has the deepest mines in the world and the exploratory holes are drilled through continuous coring system (Walker and Millheim, 1990). For example, the AngloGold Ashanti gold mine outside Carletonville, South Africa, is around 3,600 m deep (Bar-Cohen and Zacny, 2009).

In mineral exploration, the main purpose of drilling is to acquire large number of samples to obtain information about the vertical and lateral distribution of the geological formation, the structural regime, ore and its grade. This would determine if the site is feasible for further investigations and studies. Currently, reverse circulation (RC) and diamond coring are the two typical drilling methods which are used (Atlas-Copco, 2010; Marjoribanks, 2010). The first method provides small size to powder like samples, whereas with the latter technique cores can be retrieved. In the RC method the energy is provided by the hammer through pneumatic percussion action to the bit instead of rotating the entire drilling rods, and is faster and more flexible than coring and provides virtually uncontaminated cuttings (ranges from dust to $2.5 \mathrm{~cm}$ chips) suitable for geochemical anomalies. In diamond coring, a hollow bit, usually impregnated diamond, is used to cut the rock through rotary motion with the purpose of extracting core to increase our knowledge about the geology of the rocks and the 3D extension and distribution of the ore body. 
RC drilling compared to core drilling, has two shortcomings. Firstly, because of the increase in air pressure required with hole depth there is a limit to drilling up to the depth of $800 \mathrm{~m}$ using multiple air compressors to supply the drill rig. Secondly, RC drilling yields less information about geological structure of the ore body. Diamond drilling can routinely achieve depths in excess of $1,200 \mathrm{~m}$, and as it goes deeper, twist-offs of the small-diameter drill pipe is a major problem with this system. The depth capacity of the diamond coring rig is set by at least two factors: pull force and torque (Atlas-Copco, 2010).

Currently, mine operators mostly use RC for drilling shallow holes and in-pit grade control to clearly define surface geochemical anomalies, and core drilling for deeper holes to identify future resources if the area is geologically complex or the exposure is poor (Marjoribanks, 2010). Selecting the right technique or combination of techniques is always a trade-off between speed, cost, required sample quality, sample volume; logistics and environmental considerations. However, the best method for drilling is the one which reduces the sampling time and costs and achieves the best quality samples (Atlas-Copco, 2010).

When drilling to extreme depths with diamond coring system, the drill pipes will encounter intense friction due to larger contacts between drill pipes and the hole wall, so that drill bit efficiency will be lost as power transferred to the bit from the rig surface top drive system lessens. Drilling efficiency and core recovery will also be more likely to decrease and the core sample damaged by problems such as the stick-slip phenomenon. Thus, more power at the bottom of the borehole will be required for extremely deep hard rocks formations.

With respect to the purpose of mineral exploration, drilling small size holes as fast as possible and obtaining the samples to the surface would be a good alternative with several advantages over conventional drilling methods. As a result, the use of coiled tubing (CT), which is a continuous length of pipe with no connection, has been proposed for mining drilling applications. CT has been initially used in oil and gas industry for stimulation and work-over operations but its applications was extended to drilling micro-boreholes recently (Albright, Dreesen and Anderson, 2003; Albright, Clough and Dreesen, 2003; Cohen and Deskins, 2005; Galbierz and Oglesby, 2005; Theimer and Kollé, 2007; Dietrich et al., 2009).

Contrary to conventional drilling, in CT drilling the pipe cannot rotate and hence a down hole motor is required to provide the rotation and power to the bit. It is discussed in this paper why using a turbine down hole motor (turbodrill) is necessary for drilling hard rocks at high depth for mineral exploration purposes. Also, for hard rocks drilling impregnated diamond bits with small depth of cut (DOC) must be used for an efficient drilling. CT drilling using an impregnated diamond bit with a turbine down hole motor will result in a more economical alternative drilling method which compensates the high costs of the turbodrill comparing to other existing motors. This is due to the fact that using this combination, the number of trips for changing wear or dull bit or failed motors will reduce significantly. The right balance between the system of the bit, Bottom hole assembly (BHA), drilling parameters and formation is the main driver for ROP enhancement (Gantt, Erin and Leising, 1998; Portman, 2000; Precision-Energy-Services, 2000; Williams and Deskins, 2001; Noynaert, Pumphrey and Pink, 2007; Eren, 2010; Dupriest et al., 2011; Dykstra, Schneider and Mota, 2011). As a result, in this study the BHA components are proposed for a typical borehole drilling for hard rocks mineral exploration.

\section{Coiled tubing drilling}

Coiled Tube (CT) is a continuous length of ductile steel or composite tube that is stored and transported over a large reel (see Figure 1), in which the reel diameter must be at least 40-48 times the diameter of the tubing, to avoid excessive stress (CTES, 2005; ICoTA, 2005; NETL, 2005). The CT Unit (CTU) consists of four basic elements: 1) Reel, for storage and transport of the CT, 2) Injector Head, to provide the surface drive force to run and retrieve the CT, 3) Control Cabin, from which the equipment operator monitors and controls the CT, and 4) Power Pack, to generate hydraulic and pneumatic power required to operate the CT unit. Tube sizes for 
drilling purposes range from $2.54 \mathrm{~cm}\left(1 \mathrm{in}\right.$.) to $11.4 \mathrm{~cm}\left(4 \frac{1}{2} \mathrm{in}\right.$.), and with an average yield strength of 344.7 $\mathrm{MPa}(50,000 \mathrm{psi})$ to $827.4 \mathrm{MPa}(120,000 \mathrm{psi})$ (NETL, 2005). The bigger the CT diameter, the deeper it can be used but the more it weighs and the less its life would be. It can be uncoiled in the well and returned back to the reel up to 50 or more times depending to the drilling conditions before metal fatigue forces retirement (MEDC; CTES, 2005; NETL, 2005). In oil and gas industry, the basic micro-drilling rig concept was developed by the U.S. Los Alamos National Laboratory LANL (Albright, Dreesen and Anderson, 2003; NETL, 2005) to achieve a readily automated coiled tubing deployed drilling model to provide an inexpensive, reliable, and field demonstrated in range of 4.45 to $6.03 \mathrm{~cm}$ diameter holes to the depth of 200-300 m.

In the following sections some advantages and disadvantages of CT and parameters affecting the CT life are listed.

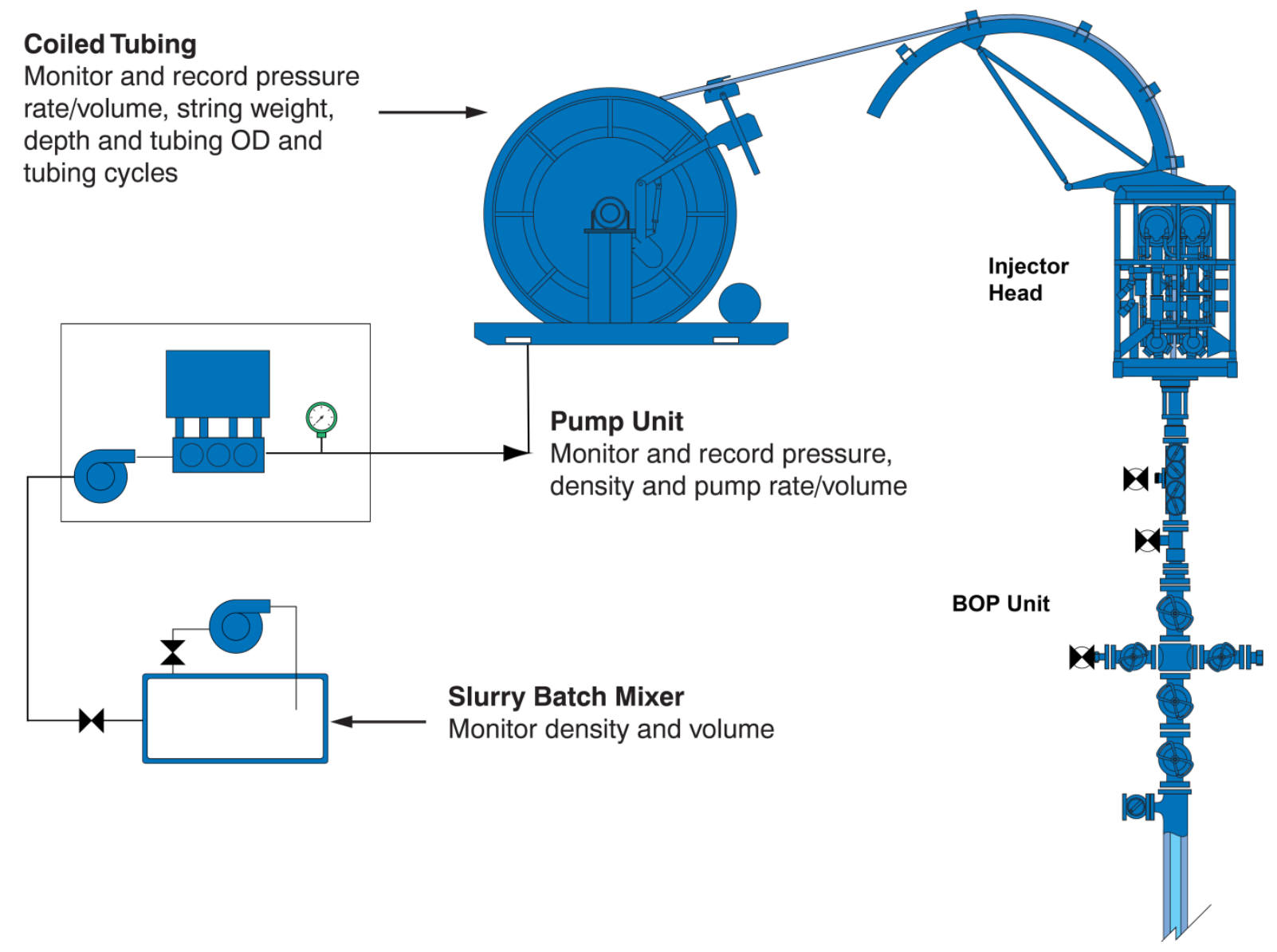

Figure 1: A schematic view of coiled tubing unit, after CTES manual (CTES, 2005).

\subsection{Coiled Tube drilling: advantages, disadvantages and limitations}

Coiled Tube (CT) drilling has several advantages and limitations in comparison to conventional drilling method in oil and gas industry, (Pierce, Livesay and Finger, 1996; Byrom, 1999; NETL, 2005). Some of these are listed below with reference to mineral exploration applications.

\section{Advantages:}

- Fast tripping, up to 2.5 times faster than with drill pipe (current world record is $254 \mathrm{~m} / \mathrm{hr}$ ).

- A big derrick is not required for handling drill pipes, so surface equipment and its footprint can be reduced.

- Fewer crews required for operation (2 man crew can manage the drilling operation). 
- It would be relatively simple to incorporate an electrical conductor into coiled tubing. This would facilitates drilling with electric motors, using active down hole steering tools, and collecting real-time, high-bit-rate down hole data (Anderson, Dorel and Martin, 1997; Turner et al., 1999; Turner et al., 1999).

- More effective in precise positioning of tools in horizontal and vertical wells.

- Drilling fluid can be pumped continuously without any interruption due to the rod handling and this reduce the cuttings transport problem and consequently it is possible to reach higher ranges of ROP (Elsborg, Carter and Cox, 1996).

\section{Disadvantages and limitations:}

- Since the CT does not rotate, a down hole motor (which is expensive) must be used for drilling.

- Lack of pipe rotation also increases the possibility of differential sticking.

- Hole size and down hole hydraulics are limited by currently available tubing sizes (Blount, 1994).

- Weight-on-bit and torque are limited.

- The tubing is deformed plastically in bending around a relatively small radius, so pipe fatigue limits the number of trips for any piece of tubing. The tubing life is 30-50 wells for shallow $(<1000 \mathrm{~m})$ boreholes. The tubing life limits cycling.

- $\quad$ CT hoisting capacity is limited by the injector that controls the penetration rate and insures the tubing is in tension, not compression.

- $\quad$ Rig dimensions are limited by highway regulations.

- Limitation on how far the CT can be pushed (pulled) horizontally, even with tractors and equalizers.

- In hard rocks drilling, providing sufficient WOB will be difficult. (This is why we need to build low WOB cutting tools).

\subsection{Coiled Tube life and material}

Various parameters may affect the life of a CT unit. The number of times in which CT is subjected to stresses higher than the minimum yield stress will affect when travelling from the reel to the gooseneck and from the gooseneck into the injector. Internal CT pressure induces further hoop (circumferential) and radial stresses and could affect CT life. Also, the size of the CT unit and the radius of curvature over which the CT is being bent (CT reel diameter) could affect its life (MEDC; CTES, 2005).

Both fatigue testing and computer modelling show that CT working life increases with (CTES, 2005):

- Increasing tubing wall thickness,

- Decreasing tubing outer diameter (OD),

- Increasing guide arch radius,

- Using the largest reel diameter available,

- Reducing CT internal pressure during trips,

- Increasing material yield strength (at low pressure, higher stresses are generated in higher strength tubing that can cause shorter fatigue lives).

The CT manufacturing companies are working on corrosion resistant alloy (CRA) CT materials. The fatigue life of the CRA material is approximately triples the life of conventional steel CT (CTES, 2005). Another alternative to steel for manufacturing $\mathrm{CT}$ is a composite made of fibres embedded in a resin matrix. In comparison to carbon steel, composite $\mathrm{CT}$ has high resistance to fatigue damage, capability to include electrical conductors or optical fibres, and also is impervious to corrosion and significantly lighter than steel CT. However, it is 3-5 times more expensive and has maximum operating temperature of $120{ }^{\circ} \mathrm{C}\left(250{ }^{\circ} \mathrm{F}\right)$ and significantly lower stiffness than carbon steel, which means critical buckling force is much lesser (CTES, 2005). 


\section{Bottom hole assembly for CT drilling in hard rocks}

One of the largest obstacles to greater use of coiled tubing in drilling operations is the inability to rotate, thus requiring the use of down hole drilling motors. There are many special criteria that are associated with the successful implementation of down hole motors with CT operations. One major concern when running a CT job is that it is often difficult to get enough weight on bit (WOB) to maximize the rate of penetration (ROP) through the drilling interval (Sanchez, Samuel and Johnson, 1996; Blount et al., 1998; Maehs, Law and Pruitt, 2005; Newman, Kelleher and Smalley, 2007). There are two main hydraulic down hole motors: Positive Displacement Motor (PDM) and Turbine, which convert hydraulic energy provided by the drilling fluid into mechanical energy (Lyons and Plisga, 2005).

Since CT is not very resistant to buckling loads, getting weight transferred to the bit for drilling plays a vital role in drilling directionally complex boreholes. In addition, the ROP of a fixed cutter drill bit is a product of the depth of cut (DOC) and the rotation speed (RPM) and that the DOC is primarily produced by the available WOB, in an environment where WOB is limited (as with CT drilling); high RPM is the key driver for ROP (Beaton and Seale, 2004; Seale, Beaton and Flint, 2004; Judzis et al., 2006; IT, 2007; APS, 2008; Grigor, Conroy and Henderson, 2008; Mushovic et al., 2009; Schlumberger, 2010; Radtke et al., 2011; Staley et al., 2011). As a result, Amongst available down hole motors, turbodrills (turbine motors) are the best choice to be used for small size CT drilling hard rocks (Mokaramian, Rasouli and Cavanough, 2012): this results in a smooth borehole with little vibrational effects during drilling.

In general, the down hole turbine motor (Turbodrill) is composed of two sections: turbine motor section and bearing section i.e. thrust-bearing and radial support bearing (Eskin and Maurer, 1997). Figure 2 shows a typical Turbodrill assembly and the fluid flow path through turbine stages. Sometimes a special section is used at the top of the motor to provide a filter to clean up the drilling mud flow before it enters the motor, or to provide a by-pass valve (Cavo, 2005). The turbine motor section has multistage of rotors and stators, from as few as 25 to as many as 300 (Lyons and Plisga, 2005). The main operating parameters that dictate the size of the turbine motors are torque, speed, and mud weight (Sanchez, Samuel and Johnson, 1996). 


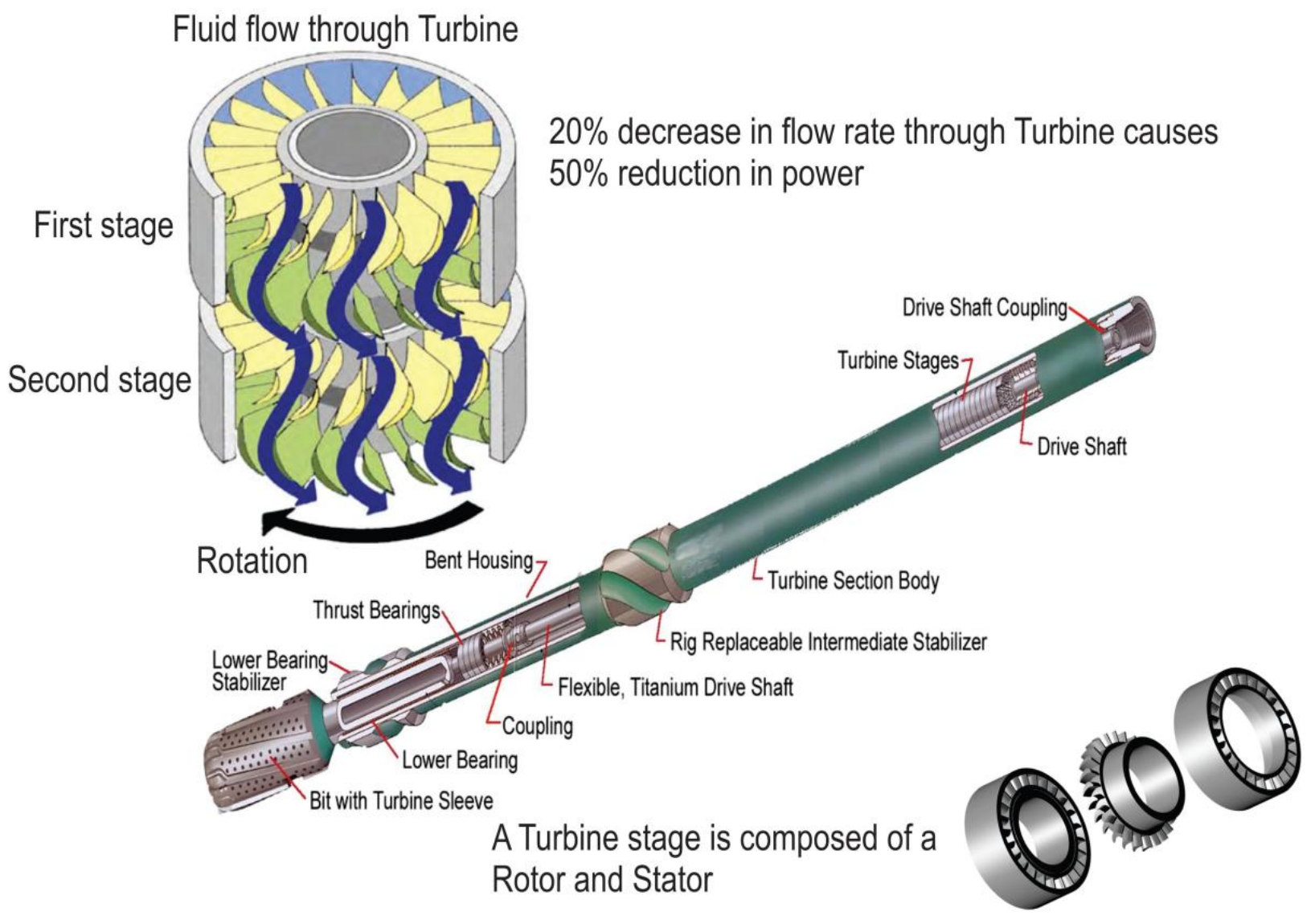

Figure 2: Turbodrill assembly and fluid flow through turbine stages (after (Beaton and Seale, 2004) and (Calnan, Seale and Beaton, 2007)).

Many new turbodrill designs and modifications are currently underway to extend the applicability of Turbodrilling to coiled tubing operations (Seale, Beaton and Flint, 2004; Grigor, Conroy and Henderson, 2008; Radtke et al., 2011). One of the most significant developments in progress is the creation of a turbodrill that is much shorter than existing designs in order to enhance compatibility with coiled tubing equipment. Other developments currently underway to improve their compatibility with CT drilling applications include specially designed turbine blades for these applications. These blades are being designed to maximize power output in the shortest possible tool configurations. Inefficient blade shapes generate losses in the process of converting hydraulic to mechanical energy. Three dimensional modelling, computational fluid flow analysis and similar modern engineering tools have enabled step improvement in turbine blade performance and give engineers the capability to optimize blades to specific fluid characteristics and flow rates (Eskin and Maurer, 1997; MaurerEngineering-Inc., 2000; Natanael et al., 2006; Calnan, Seale and Beaton, 2007; Natanael et al., 2008; Radtke et al., 2011).

Having no elastomers in the system, the turbodrill is also well suited for performing in high temperature environments, where other down hole motors frequently fail. The concentric design of the turbodrill power shaft also makes it more efficient for use with CT. When drilling or milling, the turbodrill has little vibration, so there is little lost energy in the system (Maurer et al., 1977; DeLucia and Herbert, 1984; Reich et al., 2000; Beaton and Seale, 2004; RIO, 2004; Regener et al., 2005; Seale and Conroy, 2005; Langille, Deen and Klassen, 2009; Mushovic et al., 2009; Barton, Baez and Gee, 2011).

As explained above when the rock is ultra-hard or abrasive, for the rotary CT drilling, the best matched combination of bit and motor is diamond impregnated bit with turbine motor. Although the ROP with diamond impregnated bits is low due to low level of DOC, it can be improved through a high RPM provided by turbine. 
Currently there is no small size turbodrill $(<7 \mathrm{~cm})$ available in the market suitable for small borehole mineral exploration drilling (Radtke et al., 2011). As a result, design and fabrication of small size turbodrill is a needed development in this area.

Diamond impregnated bits, commonly referred to as impregs, drill rocks by grinding action. Impregnated diamond bits are the most commonly used bits in mineral exploration drilling. Diamonds smaller than a few millimetres are imbedded in a tungsten carbide binder, allowing them enough exposure to grind away a small amount of formation at a time, until the dull, break out, and fresh diamonds are exposed. However, diamond size, type, concentration within the substrate, and alloy properties of the substrate are also regularly optimized. In addition, recent technology allows diamonds to be spatially oriented within the substrate, mitigating inconsistencies created by having high and low concentration regions within the substrate (Langille, Deen and Klassen, 2009; Franca and Lamine, 2010).

Proper BHA design for CT drilling is essential in keeping the hole straight and cause lower vibration and better hole quality which means better tool face control, better steerability, improved weight transfer to the bit, and more constant bit-rock interactions (Maranuk et al., 2000; Maehs, Law and Pruitt, 2005; Newman, Kelleher and Smalley, 2007; Staley et al., 2011). Hole spiralling can occur with both steerable motor assemblies and rotary assemblies (DeLucia, 1989). To mitigate or reduce this the best way to drill a high-quality wellbore is to use extended-gauge bits (Gaynor, 1988; Chen, Gaynor and Comeaux, 2002).

Considering the fundamental differences in drilling hard rocks in mineral exploration comparing to oil and gas wells, the BHA should be adapted for CT drilling in mineral exploration applications. The design should be with the objective of delivering reliable samples to the surface with cheaper, quicker and safer drilling. Accordingly, the main components of a drilling assembly, from bit up to the CT unit at the surface are presented in the next subsection.

\subsection{Specifications of BHA for CT drilling in hard rocks}

The adoptions suggested here are required to make the BHA components suitable for mineral exploration drilling applications. Figure 3 shows a schematic CT unit with main components.

\section{Drill bit}

- An impregnated diamond bit which is designed for high rotary speed, low WOB drilling. The bit must be compatible with formation properties, the coil and the motor. In high rotation speed, cooling improvement of impregnated bit is very important.

- For the applications with high speed motors, bits with a long gauge should be used to prevent a spiral hole and to replace the near bit stabilizer which is used to wear down very quickly at high RPM, especially in deviated wells (Chen, Gaynor and Comeaux, 2002).

- Matrix hardness, diamond size and dosing can be varied according to the rock which must be cut. The nozzles allow water to be delivered to the cutting face. This provides three essential functions: lubrication, cooling, and removal of drill cuttings from the hole (Atlas-Copco, 2010).

- Proper flow rate and bit hydraulics calculations are essential to obtain desired depth of cut and should have a proper relation with the bit RPM. At high bit RPM, the flow rate must be sufficient to clean the cutting bed before the subsequent segment of the impregnated bit re-drills the cuttings. An increase in flow rate leads to clean out of this bed, resulting in a higher depth of cut. 


\section{Down hole Motor}

- A high power and ultra-high rotation speed Turbodrill is required for hard rocks CT drilling. The turbine motor should deliver high rotation speed suitable for impregnated diamond bit with low DOC to cause high range of ROP.

- The overall dimensions of the motor limit the motor power output. A two-fold decrease of motor diameter decreases torque per unit length in a turbodrill 3-fold (Eskin and Maurer, 1997).

- Due to its hydrodynamic function the power output of a turbine is not linear with the flow rate. A $20 \%$ reduction in mud flow reduces the power output by $50 \%$, which drastically reduces ROP in all deep wells, small size holes (Reich et al., 2000).

- Optimum rotational speed for a turbine motor is presently 1,000-2,000 RPM depending on the type of applications (IT, 2007). For hard rocks mineral exploration applications the existing turbines need to be modified to provide optimum rotation speeds of higher than 2,000 RPM.

\section{Bottom hole assembly (BHA)}

- Two types of BHA assembly are needed to be used with CT unit for different sampling purposes, one for coring and another for full bit face drilling.

- The drilling BHA will provide reliable cutting samples even with depth accuracy of less than 1 metre depending on the drill depth, annular velocity, mud viscosity etc. (Georgi, Harville and Robertson, 1993). However, some degree of cuttings dispersion and contamination of the sample is inevitable.

- The coring BHA is only used for particular intervals which are crucial to be cored due to CT susceptibility to number of trips for retrieving the cores.

- Coring during turbine drilling with conventional core barrels attached to the turbodrill shaft proved to be very difficult, and high vibration levels often breaks the core in the core barrel (Eskin and Maurer, 1997).

- Special Turbo-corer is needed. This consists of a turbodrill fitted with a hollow shaft which houses a detachable core holder (Eskin and Maurer, 1997).

\section{CT Unit}

- The maximum stall torque of the motor should not exceed $80 \%$ of the nominal torsional yield of the tubing for vertical drilling, and 50\% of the nominal yield for drilling directional boreholes (CTES, 2005).

- The required mast height for handling the BHA components is dictated by the maximum anticipated drilling motor length since these are likely to be the longest components that will need to be inserted. 


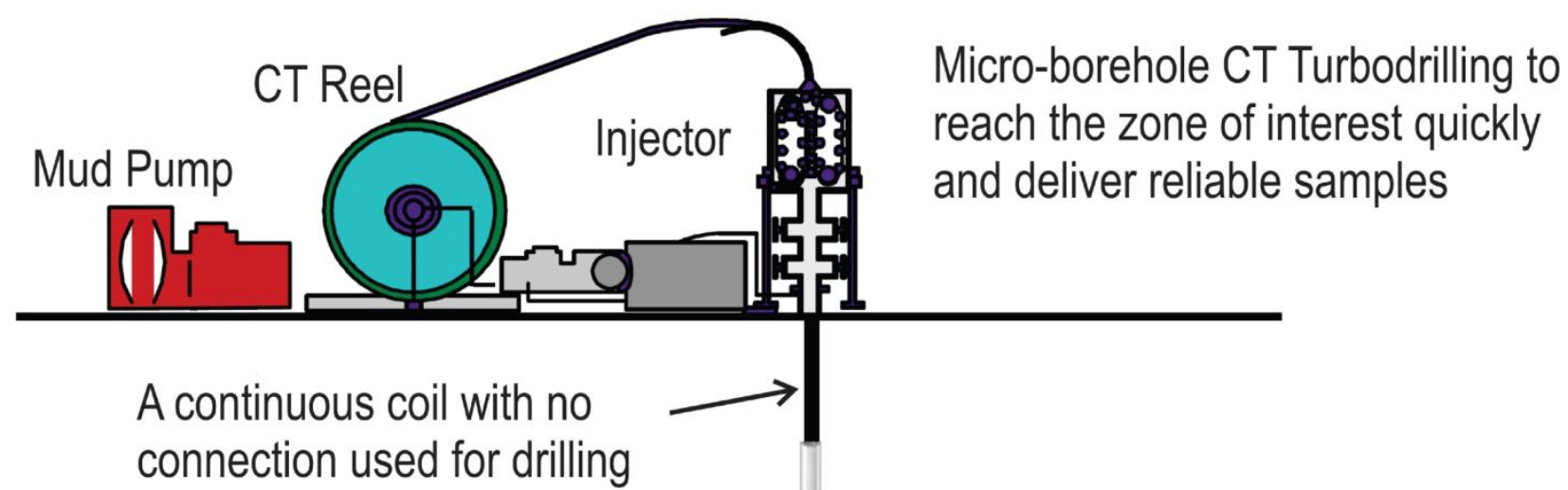

A downhole turbine motor is used to rotate the bit

Impregnated bit must be used for drilling in hard and abrasive rocks

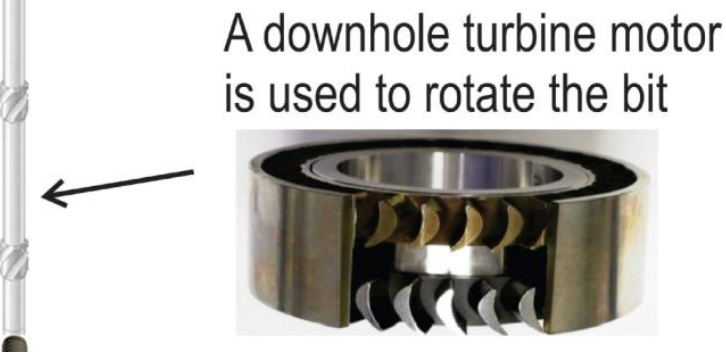

Figure 3: A schematic coiled tubing unit with BHA assembly for hard rocks mineral exploration drilling.

\section{System design for CT Turbodrilling in hard rocks}

The design of engineering components of a CT system for hard rocks drilling is affected by several parameters. Some of the engineering design factors to be considered for CT drilling of hard rocks in small size holes are listed below:

1. The minimum borehole diameter to drill is limited to an order of $5.08 \mathrm{~cm} \mathrm{(2} \mathrm{in)} \mathrm{to} 7.62 \mathrm{~cm} \mathrm{(3} \mathrm{in)} \mathrm{at}$ depths deeper than $1000 \mathrm{~m}$. This is due to the limitations of the hydraulic system (Dietrich et al., 2009).

2. Considering a relatively large ratio for the outside tubing to borehole diameter increases the allowable bit thrust that can be applied before buckling occurs (Qui, Miska and Volk, May 1998). A two-thirds ratio, as opposed to a more traditional one-half ratio in use for conventional drilling systems, achieves an optimum hydraulic power transport to the BHA based on simple power law simulation of the circulating flow loop (Albright, Dreesen and Anderson, 2003).

3. The CT reel diameter must be at least 40-48 times the diameter of the tubing, to avoid excessive stress (CTES, 2005).

4. The flow rate will have to be high enough to keep the cuttings concentration at any point in the annulus well below $5 \%$ by volume at the maximum desired penetration rate. High concentrations will result in excessive pressure losses due to particle interactions (Albright, Dreesen and Anderson, 2003).

5. The general rules for annular velocity in the vertical section is $0.2 \mathrm{~m} / \mathrm{s}(40 \mathrm{ft} / \mathrm{min})$ and a maximum pumping pressure of $27,579 \mathrm{KPa}(4,000-p s i)$ is usually used. Exceeding the 4,000 psi pumping pressure results in shortening the fatigue life of the coiled tubing. When ROPs are high, the minimum annular flow velocity may need to be increased to prevent loading up the hole with solids and increasing the equivalent circulation density (ECD) (CTES, 2005).

6. It is almost impossible to determine formulae for turbines under working conditions. Laboratory experiments using drilling dynamometer test stand have to be conducted to determine nominal data on turbodrills. When designing a hydraulic multistage turbine, it is assumed that each turbine stage is 
identical, i.e. the flow rate, pressure drop, rotary speed, generated torque, and power transmitted to the shaft are the same for each of the stages (Eskin and Maurer, 1997). In mathematical term this can be written as:

$$
\begin{aligned}
& N \propto Q ; T \propto Q^{2} ; \Delta P \propto Q^{2} ; P \propto Q^{3} ; \eta \propto \frac{1}{Q} \\
& N \propto \frac{1}{\rho} ; T \propto \rho ; \Delta P \propto \rho ; P \propto \rho ; \eta \propto \frac{1}{\rho}
\end{aligned}
$$

where:

$N=$ Turbodrill output rotation speed (revolution per minute)

$P=$ Turbodrill output power

$T=$ Turbodrill output Torque

$Q=$ Flow rate

$\Delta P=$ Turbodrill differential pressure

$\eta=$ Turbodrill efficiency

$\rho=$ Mud density

In following subsections, the required power and hydraulic calculations for CT drilling using a turbine for a typical hard rocks drilling for mineral exploration purposes are presented.

\subsection{Power design}

We discuss this in two different sections below.

\subsubsection{Bit-rock interactions}

The bit-rock interface and interaction laws determine the amount of the mechanical power that an impregnated diamond bit requires for efficient drilling and delivering the desired range of ROP. In a model of the drilling response for drag bits, a set of relations between the WOB $(W)$, the torque-on-bit, TOB, $(T)$, the ROP $(V)$, and the angular velocity $(\Omega)$ characterize the bit-rock interactions (Detournay and Defourny, 1992; Detournay, Richard and Shepherd, 2008). This model proposes three successive regimes in the drilling response of the bit. Phase I, at low DOC per revolution, is characterized by dominance of the frictional contact process and by an increase in the contact forces with the DOC $(d)$. Phase II refers to the regime where the contact forces are fully mobilized and the desired range of DOC are achieved. In phase III, the actual contact length increases, due to poor cleaning or excessive DOC. The drilling response model for a typical mode consists of a set of relationships between $W, T, V$, and $\Omega$.

The rate-independent bit-rock interface laws is expressed in terms of dynamic quantities, a scaled weight $w$ and torque $t$, and on the DOC per revolution, $d$, which is proportional to the velocity ratio $V / \Omega$. These three basic state variables are defined as:

$$
\begin{aligned}
& w=\frac{W}{a} \\
& t=\frac{2 T}{a^{2}}
\end{aligned}
$$




$$
d=\frac{2 \pi V}{\Omega}
$$

where $a$ is the bit radius. Scaling of the weight and torque removes the influence of the bit dimension from the interface laws. The scaled quantities $w$ and $t$, which have dimensions of force/length (a convenient unit is the $\mathrm{N}$ $\mathrm{mm}^{-1}$ ), can conveniently be interpreted as the normal and shear force per unit length on a two-dimensional cutter removing material over a $\operatorname{DOC}(d)$.

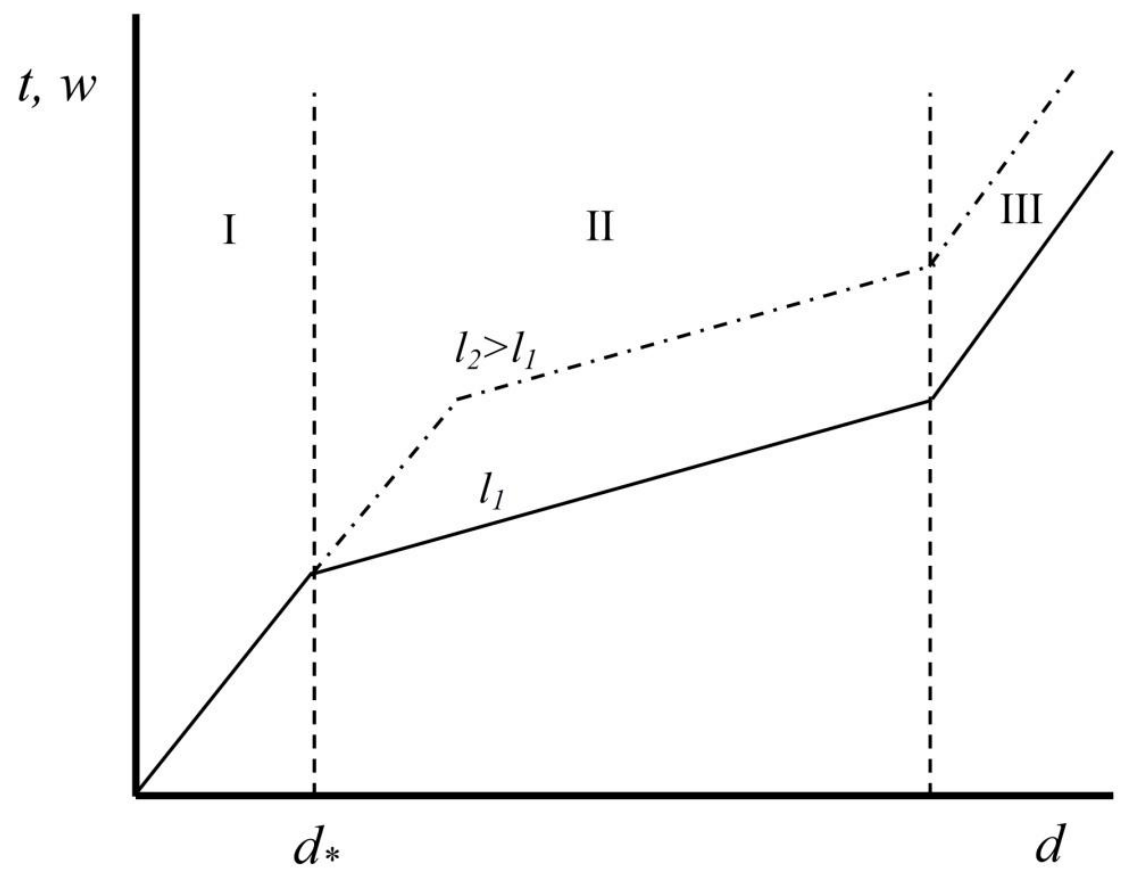

Figure 4: Conceptual drilling response of the bit-rock interaction (after (Detournay and Defourny, 1992), (Detournay, Richard and Shepherd, 2008)).

Figure 4 shows a conceptual drilling response characterized by three distinct phases as explained before in the plot of $w$ and $t$ versus $d$. The extent of phase I $\left(d_{*}\right)$ is controlled by the tool state of wear $d_{*}=d_{*}(l)$, in which $l$ is the length of wear contact, and various experimental results suggest that $\frac{l}{20}<d_{*}<l$. In phase 2 , where the desired range of DOC is achieved, the rubbing force is assumed constant and the governing equations for this phase are:

$$
\begin{aligned}
& w=\zeta \varepsilon d+\sigma l \\
& t=\varepsilon d+\mu \gamma \sigma l
\end{aligned}
$$

where $\varepsilon$ is the intrinsic specific energy (the minimum amount of energy required to remove a unit volume of rock). For impregnated bits $\varepsilon$ is assumed to be $5 q$, where $q$ is the rock uniaxial compressive strength. Also $\zeta$ is a number that characterises the inclination of the cutting or fragmenting force, which usually for impregnated bits is assumed to be 3-4, and here is assumed to be 4 . Here, $\sigma$ is the contact stress, which is equivalent to $q$. In this equation $\mu$ is the friction coefficient, which for impregnated bits it is assumed to be in the range of 0.05 0.1 . Also, $\gamma$ is the bit number, which for the sake of simplicity, it is assumed to be 1 .

As previously explained, for CT drilling in hard rocks, it is preferred to design the drilling system for ultra-high rotation speeds (i.e. $N>2,000 \mathrm{RPM}$ ) and very low DOCs in the range of $0.01-0.1 \mathrm{~mm} / \mathrm{rev}$. For calculation 
purposes we assume $\mathrm{ROP} \cong 5 \mathrm{~m} / \mathrm{hr}$ at a rotation speed of $N \cong 3-4(\mathrm{Krpm})$, in phase II of Figure 4 . This results in a DOC of:

$d\left(\frac{m m}{r e v}\right)=\frac{R O P\left(\frac{m}{h r}\right) \times 16.7}{N(r p m)}=\frac{5 \times 16.7}{4000}=0.021 \frac{\mathrm{mm}}{r e v}$

If $l \cong 0.1(\mathrm{~mm})$ and $d \cong 0.02-0.03\left(\frac{\mathrm{mm}}{\mathrm{rev}}\right)$, according to the equations representing phase II for very hard rocks (e.g. American Black rock has a UCS of around $300 \mathrm{MPa}$ ), and the range of parameters mentioned above, the scaled weight and torque will be:

$w \approx(150-300)\left(\frac{N}{m m}\right) ; t \approx(50-100)\left(\frac{N}{m m}\right)$.

Consequently, being in the conservative side, in this study we consider:

$w \cong 300\left(\frac{N}{m m}\right)$, and $t \cong 100\left(\frac{N}{m m}\right)$.

From these parameters $a, W O B$ and $T$ are calculated as:

$a=\frac{O D_{B}}{2}=\frac{3 \text { in }}{2}=1.5 \mathrm{in}(38.1 \mathrm{~mm})$

$w=\frac{W}{a} \Rightarrow W O B=300 \times 38.1=11,430 N$

$t=\frac{2 T}{a^{2}} \Rightarrow T=\frac{100 \times(38.1)^{2}}{2}=72,580 \mathrm{~N} . \mathrm{mm}=72.6 \mathrm{~N} . \mathrm{m}$.

\subsubsection{Turbodrill output power}

The angular power $P$ at the bit required to drill is simply given by (Rabia, 1985):

$$
P=T \times \Omega
$$

with $\Omega$ being the bit angular velocity ( expressed in $\mathrm{rad} . \mathrm{s}^{-1}$ ). This equation can be written in the following form (Bourgoyne Jr. et al., 1986):

$$
P_{m}(K W)=\frac{T(N . m) \times N(r p m)}{9,550}
$$

If the rotation speed is assumed to be $N \cong 4,000(\mathrm{rpm})$, then:

$P_{m}=\frac{72.6 \times 4,000}{9,550}=30.4 \mathrm{KW}(40.8 \mathrm{hp})$

The down hole motor output power should be adequate to provide the required power by bit. This is to say that:

$$
P_{\text {hyd }} \geq P_{m}
$$

The hydraulic power generated by turbodrill $\left(P_{h y d}\right)$ is calculated as (Lyons and Plisga, 2005):

$$
P_{h y d}(h p)=\frac{Q(g p m) \times \Delta P(p s i)}{1,714} \times \eta_{m}
$$


where $\eta_{m}$ is the Turbodrill efficiency, which is usually considered 0.5-0.6, (Eskin and Maurer, 1997).

Here, we use $\eta_{m}=0.6$, and the mud flow rate for the current application is considered to be $Q=90 \mathrm{gpm}(341 \mathrm{lpm})$. This would lead to the Turbodrill shaft power $\left(P_{M}\right)$ of:

$P_{M}=\frac{P_{h y d}}{\eta_{m}}=\frac{40.8}{0.6}=68 \mathrm{hp}(51 \mathrm{KW})$

And the motor pressure drop of:

$\Delta P=\frac{P_{M} \times 1,714}{Q}=\frac{68 \times 1,714}{90}=1,295 p s i(8,929 \mathrm{KPa})$

\subsection{Bottom hole assembly:}

The specifications of the CT unit and BHA components for a typical deep drilling in hard rocks for mineral exploration purposes as per above information are proposed as:

CT outside diameter $\left(O D_{C T}\right)=5.08 \mathrm{~cm}(2 \mathrm{in})$

CT inside diameter $\left(I D_{C T}\right)=4.4 \mathrm{~cm}(1.732 \mathrm{in})$

CT total length $\left(L_{C T}\right)=2,500 \mathrm{~m}(8,202 \mathrm{ft})$

Final drilling depth $(\mathrm{DD})=2,400 \mathrm{~m}(7,874 \mathrm{ft})$

CT reel diameter $\left(D_{\text {reel }}\right)=48 \times\left(O D_{C T}\right)=48 \times 2$ in. $=96$ in $(2.44 \mathrm{~m})$

Drill collar outside diameter $\left(O D_{D C}\right)=6.35 \mathrm{~cm}(2.5 \mathrm{in})$

Drill collar inside diameter $\left(I D_{D C}\right)=2.54 \mathrm{~cm}(1$ in $)$

Downhole motor diameter $\left(O D_{M}\right)=6.35 \mathrm{~cm}(2.5 \mathrm{in})$

Bit diameter $=O D_{B}=7.62 \mathrm{~cm}(3$ in $)$

Drill collar length should be enough to provide desired WOB and can be calculated as:

$w_{D C}\left(\frac{l b m}{f t}\right)=\frac{\pi \times\left(O D_{D C}^{2}-I D_{D C}^{2}\right)}{4 \times 144} \Rightarrow w_{D C}=16.7\left(\frac{l b m}{f t}\right)=24.9\left(\frac{\mathrm{kg}}{\mathrm{m}}\right)$.

The buoyancy effect of the drilling mud will decrease the effective WOB provided by drill collar. The drilling mud used is fresh water without fine particles to be suitable for Turbodrill motor. The effective weight is calculated as:

mud density $=\rho_{w}=8.4\left(\frac{\mathrm{lb}}{\mathrm{gal}}\right)=1,007\left(\frac{\mathrm{kg}}{\mathrm{m}^{3}}\right)$

steel density $=\rho_{s}=65.5\left(\frac{\mathrm{lb}}{\mathrm{gal}}\right)=7,849\left(\frac{\mathrm{kg}}{\mathrm{m}^{3}}\right)$

effective weight $=w_{e}=w_{D C} \times\left(1-\frac{\rho_{w}}{\rho_{s}}\right)=21.7\left(\frac{\mathrm{kg}}{\mathrm{m}}\right)$. 
The neutral point (i.e. the transition between tension and compression force along the drill string) should be located within the drill collar to ensure that the CT is always under tension to seat within the BHA at a maximum distance from the bit of about. This point is usually considered as 0.8 times of the total drill collar length (Rabia, 1985). Therefore, the:

$W O B=0.8 \times W_{D C} \Rightarrow 11,430(N)=0.8 \times W_{D C} \Rightarrow W_{D C}=14,288(N)$.

With $w_{e}=21.7\left(\frac{\mathrm{kg}}{\mathrm{m}}\right)$, the minimum length of the drill collar will be:

$L_{D C}=\frac{14,288}{21.7}=67 \mathrm{~m}=220(f t)$.

Also due to the pressure drop across the bit, a hydraulic pump-off force will be applied to the bit which reduces the effective WOB provided by the drill collars. As a result, in order to provide the desired WOB, an equivalent length of drill collar should be added to compensate the effect of pump-off force. In this study it is assumed to lower the pump-off force as much as possible doing a careful bit design and finally the total length for drill collar is considered to be $240 \mathrm{ft}$ ( 8 strings of $30 \mathrm{ft}$ long of drill collar). This means the need for around $20 \mathrm{ft}$ of drill collar and another $40 \mathrm{ft}$ for the BHA components (i.e. motor, bit and subs) to compensate the pump-off force effect. As a result, the total length of BHA is:

$L_{B H A}=240+40=280(f t)=85.3(m)$.

\subsection{Hydraulics Calculations}

The pump pressure $\left(P_{\text {pump }}\right)$ required corresponding to a given flow rate is obtained as:

$$
P_{\text {pump }}=P_{\text {losses }}+P_{\text {saftey margin }}
$$

The subscript "losses" refers to frictional pressure losses around the flow path. The drilling fluid used in this study is considered to be fresh water with density of $\rho_{w}=8.4 \mathrm{ppg}\left(1,007 \frac{\mathrm{kg}}{\mathrm{m}^{3}}\right)$, and the flow model used here is the power-law model with constants $n=1$ and $k=0.0021$.

Equation 13 describes the pressure losses around the flow path.

$$
P_{\text {losses }}=P_{C T}+P_{B H A}+P_{\text {annulus }}
$$

The subscripts in Equation 13 identify the portions of the flow path from the pump to the choke in the return line at the surface.

The calculations for the pressure losses across different sections of the drill string are presented below.

\subsubsection{Pressure losses inside the CT}

In this section formulae for pressure losses inside the CT are provided (CTES, 2005). Equation 14 is the general form for calculating frictional pressure losses in a conduit:

$$
\Delta P=f_{H}\left(\frac{\rho V^{2} L}{2 D_{e}}\right)
$$


where $f_{H}$ is the hydraulic friction factor, $V$ is the average or bulk fluid velocity, $L$ is the length of the conduit, and $D_{e}$ is the equivalent hydraulic diameter of the conduit.

A convenient way to relate pressure losses to flow rate for $\mathrm{CT}$ is through a hydraulic friction factor. Equation 15 is the general form for CT hydraulic friction factor that applies to both straight and curved tubing:

$$
f_{H}=2\left(\frac{\Delta P}{L}\right)\left(\frac{O D-2 t}{\rho V^{2}}\right)
$$

In this equation $L$ is the length of tubing contributing to $\Delta P, \rho$ is fluid density, and $V$ is the average fluid velocity in the tubing. Determining $f_{H}$ means simply measuring $\Delta P$ for a range of flow rates and applying Equation 15. The empirical relationship between $f_{H}$ and flow rate can be used to estimate $\Delta P$ at any flow rate in the measured range assuming the fluid's properties are constant.

However, during the planning phase of CT operations, this relationship is unknown, and $f_{H}$ must be modelled. The model for $f_{H}$ depends on the rheological model for the fluid, the flow regime, and the geometry of the CT (straight or on the reel). The flow model used in this study is considered to be power-law model.

\section{Reynolds Number}

In the 1880's Osborne Reynolds proposed that the ratio of inertial force to viscous force would indicate whether a fluid flow is laminar (i.e. in the form of parallel stream lines) or turbulent (mixing or transverse flow). Equation 18 shows the dimensionless Reynolds Number for power law fluids (CTES, 2005):

$$
N_{R e}=\frac{\rho V^{(2-n)}(O D-2 t)^{n}}{K 8^{(n-1)}}\left(\frac{4 n}{3 n+1}\right)^{n}
$$

For power law fluids, the flow is laminar when $N_{R e}<(3,470-1,370 \mathrm{n})$ and turbulent when $N_{R e}>(4,270-1,370 \mathrm{n})$. In this study due to having high amount of flow rates, the flow regime throughout the drilling system is turbulent.

Equation 17 shows the hydraulic friction factor for Newtonian, power law, and Bingham plastic fluids in straight tubes (CTES, 2005).

$$
f_{H S}=\frac{a}{N_{R e}^{b}}
$$

For laminar flows, $a=16$ and $b=1$. For turbulent flows, coefficients $a$ and $b$, are calculated as:

$$
\begin{aligned}
& a=\frac{\log _{10} n+3.93}{50} \\
& b=\frac{1.75-\log _{10} n}{7}
\end{aligned}
$$

\section{Hydraulic Friction Factor for the CT on the Reel}

Equation 20 gives hydraulic friction factors for CT on a reel for power-law fluid flow (CTES, 2005):

$$
f_{H C}=\frac{1.069 a}{N_{R e}^{0.8 b}}\left(\frac{O D-2 t}{D_{\text {reel }}}\right)^{0.1}
$$

In this equation, $D_{\text {reel }}$ is the reel's core diameter. 
Taking the ratio of Equation 20 and Equation 17 gives the relationship between $\Delta P$ for $\mathrm{CT}$ on a reel compared to $\Delta P$ for the same length of straight tubing. This is expressed as:

$$
\frac{\Delta P_{C}}{\Delta P_{S}}=1.069 N_{R e}^{0.2 b}\left(\frac{O D-2 t}{D_{\text {reel }}}\right)^{0.1}
$$

From Equation 21, the effect of curvature increases with increasing flow rate $\left(N_{R e}\right)$ and decreasing reel core diameter (i.e. increasing curvature). For typical CT reels the $\Delta P$ in tubing on a reel is significantly higher (20$40 \%$ ) than that of for the equivalent length of straight tubing (CTES, 2005).

\subsubsection{Pressure losses inside the drill collars}

Considering the range of flow rate for current applications the flow regime is turbulent and therefore the pressure losses inside the drill collar for power-law fluid flow model can be represented as (Rabia, 1985):

$$
P L_{D C}=\frac{8.91 \times 10^{-5} \times \rho^{0.8} \times Q^{1.8} \times(P V)^{0.2} \times L}{D^{4.8}}
$$

where, $L$ is the total length of the drill collars.

\subsubsection{Bit Pressure drop}

The hydraulics for impregnated diamond bits should accomplish rapid removal of the cuttings, cooling and lubrication of the bit. An effective level of hydraulic energy (hydraulic horsepower per square inch) is the key to optimum bit performance. The rule-of-thumb estimation of diamond bit hydraulic horsepower and penetration rate is that for high ROP (over $10 \mathrm{ft} / \mathrm{hr}(3.048 \mathrm{~m} / \mathrm{hr})$ ), hydraulic horsepower per square inch is around 3.5 (Christensen-Inc., 1983; Lyons and Plisga, 2005). The bit hydraulic horsepower is dependent upon the pressure drop across the bit and the flow rate. The pressure drop across the bit is given by (Bourgoyne Jr. et al., 1986):

$$
P L_{B}=\frac{H P_{b} \times 1,714}{Q}
$$

For example in the case of $Q=90 \mathrm{gpm}(341 \mathrm{lpm})$, the pressure drop across the bit is calculated as:

$$
\begin{aligned}
& H P_{b}=3.5\left(\frac{h p}{i n^{2}}\right) \times A_{b}=3.5 \times \pi \times(1.5)^{2}=24.7(h p) \\
& P L_{B}=\frac{24.7 \times 1714}{90}=470(p s i)=3,241(K P a) .
\end{aligned}
$$

\subsubsection{Annulus pressure losses}

Considering the turbulent flow regime, the pressure losses across the annulus for power-law fluid flow model can be estimated as (Rabia, 1985):

$$
P L_{A n n}=\frac{8.91 \times 10^{-5} \times \rho^{0.8} \times Q^{1.8} \times(P V)^{0.2} \times L}{\left(D_{h}-O D_{p}\right)^{3} \times\left(D_{h}+O D_{p}\right)^{1.8}}
$$


where, $L$ is the annulus length between hole and BHA or CT outside diameter. $P V$ is the fluid plastic viscosity. $D_{h}$ is the hole diameter, and $O D_{p}$ is the BHA or CT outside diameter.

\subsection{Total Pressure losses}

The proposed system pressure losses are directly dependent on the flow rate. The turbodrill method suggested in this study is assumed to deliver an optimum output power of $68 \mathrm{hp}(51 \mathrm{KW})$ with a flow rate of $90 \mathrm{gpm}(341$ $\mathrm{lpm})$. The resulted differential pressure around the motor would be approximately 1,295 psi $(8,929 \mathrm{KPa})$.

The total system pressure losses are combination of pressure losses of the different sections:

$$
P L_{t}=P L_{C T-\text { curved }}+P L_{C T-\text { straight }}+P L_{D C}+P L_{M}+P L_{B}+P L_{A n n-B H A}+P L_{A n n+C T}
$$

here:

$P L_{C T \text {-curved }}=$ Pressure losses in the curved section of $\mathrm{CT}$ on the reel

$P L_{C T \text {-straight }}=$ Pressure losses in the straight section of $\mathrm{CT}$ in the hole

$P L_{D C}=$ Pressure losses in the drill collar length

$P L_{M}=$ Pressure losses around the motor (turbodrill)

$P L_{B}=$ Pressure losses in the impregnated diamond bit

$P L_{A n n-B H A}=$ Pressure losses in the annulus between BHA and the borehole

$P L_{A n n-C T}=$ Pressure losses in the annulus between $\mathrm{CT}$ and borehole

Using the formulae presented above the pressure losses calculations were carried out when the flow rate is 90 gpm (341 lpm) and the results summary are tabulated in Table 1.

Table 1: Pressure losses calculations for flow rate of $90 \mathrm{gpm}(341 \mathrm{lpm})$.

\begin{tabular}{|c|c|c|c|c|c|c|c|c|}
\hline $\begin{array}{c}\text { Pressure losses } \\
\text { (KPa) versus } \\
\text { depth (m) }\end{array}$ & $P L_{C T \text {-curved }}$ & $P L_{C T \text {-straight }}$ & $P L_{D C}$ & $P L_{M}$ & $P L_{B}$ & $P L_{A n n-B H A}$ & $P L_{A n n-C T}$ & $P L_{t}$ \\
\hline 100 & 7,802 & 249 & 2,703 & 8,929 & 3,241 & 1,173 & 30 & 24,127 \\
\hline 500 & 6,502 & 1,246 & 2,703 & 8,929 & 3,241 & 1,173 & 845 & 24,639 \\
\hline 1,000 & 4,876 & 2,492 & 2,703 & 8,929 & 3,241 & 1,173 & 1,865 & 25,279 \\
\hline 1,500 & 3,251 & 3,738 & 2,703 & 8,929 & 3,241 & 1,173 & 2,884 & 25,919 \\
\hline 2,000 & 1,625 & 4,985 & 2,703 & 8,929 & 3,241 & 1,173 & 3,904 & 26,560 \\
\hline 2,400 & 325 & 5,981 & 2,703 & 8,929 & 3,241 & 1,173 & 4,719 & 27,071 \\
\hline
\end{tabular}


To show the effect of flow rate on the total system pressure losses, in this study two other flow rates of $Q_{2}=70$ gpm (265 lpm) and $Q_{3}=110 \mathrm{gpm}(416 \mathrm{lpm})$ were considered.

According to the flow characteristics of turbodrill, the following relationships holds between output turbodrill parameters for two different flow rates (Eskin and Maurer, 1997):

$$
\frac{P_{2}}{P_{1}}=\left(\frac{Q_{2}}{Q_{1}}\right)^{3}, \quad \frac{\Delta P_{2}}{\Delta P_{1}}=\left(\frac{Q_{2}}{Q_{1}}\right)^{2}, \quad \frac{N_{2}}{N_{1}}=\frac{Q_{2}}{Q_{1}}, \quad \frac{T_{2}}{T_{1}}=\left(\frac{Q_{2}}{Q_{1}}\right)^{2}, \quad \frac{\eta_{2}}{\eta_{1}}=\frac{Q_{1}}{Q_{2}}
$$

where, $P$ is motor output power, $\Delta P$ is pressure drop across the motor, and $\eta$ is the turbodrill efficiency. And with the assumed or calculated data for $Q_{1}=90 \mathrm{gpm}$ (341 lpm) which are:

$N_{1} \cong 4,000(r p m) ; \eta_{1}=0.6 ; R O P_{1} \cong 5\left(\frac{m}{h r}\right)$

$P_{1}=68 \mathrm{hp}(51 \mathrm{KW}) ; \Delta P_{1}=1,295 \mathrm{psi}(8,929 \mathrm{KPa}) ; T_{1}=72.6(\mathrm{~N} . \mathrm{m})$

As a result, according to the equation 28 , for $Q_{2}=70 \mathrm{gpm}(265 \mathrm{lpm})$ :

$P_{2}=32 h p(24 \mathrm{KW}) ; \Delta P_{2}=783.4 \mathrm{psi}(5,401 \mathrm{KPa})$,

$N_{2} \cong 3,111(\mathrm{rpm}) ; T_{2}=21.96(\mathrm{~N} . \mathrm{m}) ; \eta_{2}=0.77$,

And for $Q_{3}=110 \mathrm{gpm}(416 \mathrm{lpm})$ :

$P_{3}=124 h p(92.5 \mathrm{KW}) ; \quad \Delta P_{3}=1,934.5 \mathrm{psi}(13,338 \mathrm{KPa})$,

$N_{3} \cong 4,888(\mathrm{rpm}) ; \quad T_{3}=54.2(N . m) ; \quad \eta_{3}=0.49$

Table 2 and 3 summarises the pressure losses calculations for two flow rates of $Q_{2}=70 \mathrm{gpm}(265 \mathrm{lpm})$ and $Q_{3}=110 \mathrm{gpm}(416 \mathrm{lpm})$, respectively.

Table 2: Pressure losses calculations for the flow rate of 70 gpm (265 lpm).

\begin{tabular}{|c|c|c|c|c|c|c|c|c|}
\hline $\begin{array}{c}\text { Pressure } \\
\text { losses }(\mathrm{KPa}) \\
\text { versus depth } \\
(\mathrm{m})\end{array}$ & $\mathrm{PL}_{\mathrm{CT} \text {-curved }}$ & $\mathrm{PL}_{\mathrm{CT} \text {-straight }}$ & $\mathrm{PL}_{\mathrm{DC}}$ & $\mathrm{PL}_{\mathrm{M}}$ & $\mathrm{PL}_{\mathrm{B}}$ & $\mathrm{PL}_{\text {Ann-BHA }}$ & $\mathrm{PL}_{\text {Ann-C }}$ & $\mathrm{PL}_{\mathrm{t}}$ \\
\hline 100 & 4,964 & 161 & 1,720 & 5,401 & 4,171 & 746 & 19 & 17,182 \\
\hline 500 & 4,136 & 803 & 1,720 & 5,401 & 4,171 & 746 & 538 & 17,515 \\
\hline 1,000 & 3,102 & 1,606 & 1,720 & 5,401 & 4,171 & 746 & 1,187 & 17,933 \\
\hline 1,500 & 2,068 & 2,408 & 1,720 & 5,401 & 4,171 & 746 & 1,835 & 18,349 \\
\hline 2,000 & 1,034 & 3,211 & 1,720 & 5,401 & 4,171 & 746 & 2,483 & 18,766 \\
\hline
\end{tabular}




\begin{tabular}{|l|l|l|l|l|l|l|l|l|}
\hline 2,400 & 207 & 3,853 & 1,720 & 5,401 & 4,171 & 746 & 3,002 & 19,100 \\
\hline
\end{tabular}

Table 3: Pressure losses calculations for the flow rate of 110 gpm (416 lpm).

\begin{tabular}{|c|c|c|c|c|c|c|c|c|}
\hline $\begin{array}{c}\text { Pressure } \\
\text { losses (KPa) } \\
\text { versus depth } \\
(\mathrm{m})\end{array}$ & $P L_{C T \text {-curved }}$ & $P L_{C T \text {-straight }}$ & $P L_{D C}$ & $P L_{M}$ & $P L_{B}$ & $P L_{A n n-B H A}$ & $P L_{A n n-C T}$ & $P L_{t}$ \\
\hline 100 & 11,197 & 354 & 3,878 & 13,338 & 2,654 & 1,683 & 43 & 33,147 \\
\hline 500 & 9,331 & 1,770 & 3,878 & 13,338 & 2,654 & 1,683 & 1,213 & 33,867 \\
\hline 1,000 & 6,997 & 3,541 & 3,878 & 13,338 & 2,654 & 1,683 & 2,677 & 34,768 \\
\hline 1,500 & 4,666 & 5,311 & 3,878 & 13,338 & 2,654 & 1,683 & 4,139 & 35,669 \\
\hline 2,000 & 2,332 & 7,082 & 3,878 & 13,338 & 2,654 & 1,683 & 5,603 & 36,570 \\
\hline 2,400 & 466 & 8,498 & 3,878 & 13,338 & 2,654 & 1,683 & 6,773 & 37,290 \\
\hline
\end{tabular}

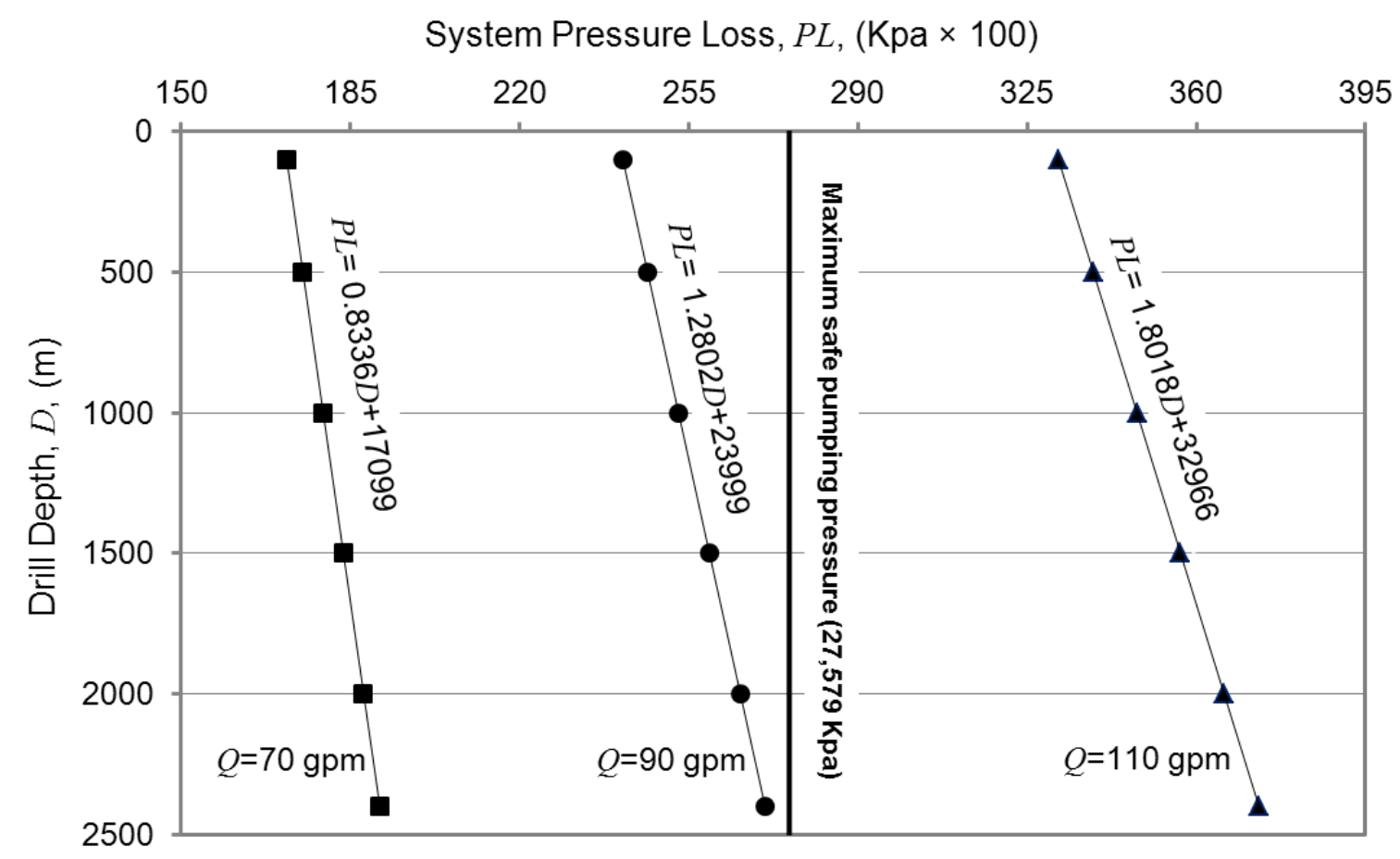

Figure 5: System pressure losses for three different flow rates versus drill depth.

The plot of CT pressure losses versus drilling depth for three different flow rates of 70, 90, and 110 gpm are shown in Figure 5. The maximum safe pumping pressure of $27,579 \mathrm{KPa}(4,000 \mathrm{psi})$ for the CT is shown as a thick vertical red line in this Figure. Exceeding this pumping pressure will result in shortening the fatigue life 
of the CT. As a result, if the final drilling depth is more than $2,000 \mathrm{~m}$ for the suggested drilling system characteristics using flow rates of higher than $90 \mathrm{gpm}(341 \mathrm{lpm})$ may not be recommended for practical purposes, and the required surface pumping pressure (output pump pressure) with taking account for safety margin, should be $27,580 \mathrm{KPa}$ for this specific drilling system. In addition, the relation between total system pressure losses and drill depth for different flow rate is linear and the line's dip will change with flow rate.

\section{Conclusions}

In this paper various aspects of adopting coiled tubing (CT) drilling for mineral exploration purposes were discussed. The benefits of CT in terms of continuous drilling and thus no need for rod handling was found important for fast, deep and cheap drilling which is the main objective in hard rocks mineral exploration. As the main objective in mineral exploration is to obtain large number of samples to test them in the lab for grade analysis it was suggested to use full bit face drilling instead of coring. A turbine down hole motor (turbodrill) was suggested to be used to transfer rotation to the bit: high rotation speed drilling with low vibration level needed for hard rocks makes the use of turbine motor necessary. Considering a typical condition for hard rocks drilling for mineral exploration the bottom hole assembly (BHA) components for CT drilling was proposed. Also, detailed power and hydraulic calculations were carried out to obtain a preliminary knowledge of expected pressure losses in the system. For comparison purposes the calculations conducted at three different mud flow rates to see how the proposed drilling system performance could be changed with the mud flow rate variations.

\section{References}

Albright, J., Dreesen, D. and Anderson, D. (2003) Road Map For A 5000-Ft Microborehole, Los Alamos National Laboratory (LANL).

Albright, J.N., Clough, J.G. and Dreesen, D.S. (2003) The Application of Microhole Technology to the Development of Coalbed Methane Resources at Remote Locations, Los Alamos National Laboratory, Division of Geological \& Geophysical Surveys, Department of Natural Resources.

Anderson, D.R., Dorel, A. and Martin, R. (1997), 'A New, Integrated, Wireline-Steerable, Bottom Hole Assembly Brings Rottary Drilling-Like Capabilities to Coiled Tubing Drilling'. Paper Presented at the SPE/IADC Drilling Conference (SPE/IADC 37654), Amesterdam, The Netherlands.

APS (2008) Novel High-Speed Drilling Motor for Oil Exploration \& Production, (APS Technology Inc.). US Department of Energy, Final Report, National Energy Technology Laboratory.

Atlas-Copco (2010) Exploration Drilling, First Edition. Sweden.

Bar-Cohen, Y. and Zacny, K. (2009) Drilling in Extreme Environments, Federal Republic of Germany, Wiley-VCH.

Barton, S., Baez, F. and Gee, R. (2011), 'Downhole Matched Solutions: Innovative Scientific Approach to More Efficient Assemblies'. Paper Presented at the SPE Asia Pacific Oil and Gas Conference and Exhibition (SPE 145980), Jakarta, Indonesia.

Beaton, T. and Seale, R. (2004), 'The Use of Turbodrills in Coiled Tubing Applications'. Paper Presented at the SPE/ICoTA Coiled Tubing Conference (SPE 89434), Houston, Texas, U.S.A.

Blount, C.G. (1994) 'The Challenge for the Coiled-Tubing Industry', Journal of Petroleum Technology (SPE 28286-PA), Vol. 46

Blount, C.G., et al. (1998), 'Weight on Bit in Coiled Tubing Drilling: Collection and Analysis of Field Data'. Paper Presented at the SPE/ICoTA Coiled Tubing Roundtable (SPE 46008), Houston, Texas.

Bourgoyne Jr., A.T., et al. (1986) Applied Drilling Engineering, Society of Petroleum Engineers.

Byrom, T.G. (1999) 'Coiled Tubing Drilling in Perspective', Journal of Petroleum Technology, Vol. 51 (SPE 51792).

Calnan, D., Seale, R. and Beaton, T. (2007) 'Identifying Applications for Turbodrilling and Evaluating Historical Performances in North America', Journal of Canadian Petroleum Technology, Vol. 46(6).

Cavo (2005) Motor Operations Manual, (Cavo Drilling Motors). Fourth Edition, Houston, Texas, U.S.A.

Chen, D.C.-K., Gaynor, T. and Comeaux, B. (2002), 'Hole Quality: Why It Matters'. Paper Presented at the SPE International Petroleum Conference and Exhibition (SPE 74403), Villahermosa, Mexico.

Christensen-Inc. (1983) 'Christensen Diamond Compact Bit Manual'.

Cohen, J.H. and Deskins, G. (2005) Advanced High-Pressure Coiled-Tubing Drilling System, Final Report, Maurer Technology Inc.

CTES, L.P. (2005) Coiled Tubing Manual, (Coiled Tubing Engineering Solutions), http://www.ctes.com. 
DeLucia, F.V. (1989), 'Benefits, Limitations, and Applicability of Steerable System Drilling'. Paper Presented at the SPE/lADC Drilling Conference (SPE 18656), New Orleana, Louieiana, USA.

DeLucia, F.V. and Herbert, R.P. (1984), 'PDM vs. Turbodrill: A Drilling Comparison'. Paper Presented at the 59th Annual Technical Conference and Exhibition (SPE 13026), Houston,Texas.

Detournay, E. and Defourny, P. (1992) '"A Phenomenological Model for the Drilling Action of Drag Bits"', international Journal of Rock Mechanics and Mining Science \& Geomechanics Abstract, Vol. 29(1): PP. 13-23.

Detournay, E., Richard, T. and Shepherd, M. (2008) 'Drilling response of drag bits: Theory and experiment', international Journal of Rock Mechanics and Mining Science, Vol. 45: PP. 1347-1360.

Dietrich, J., et al. (2009) A Feasibility Study Regarding Micro-Drilling Technology. Germany, E.ON Energy Research Center. vol 1.

Dupriest, F.E., et al. (2011) 'Borehole-Quality Design and Practices To Maximize Drill-Rate Performance', SPE Drilling \& Completion (SPE 134580).

Dykstra, M., Schneider, B. and Mota, J. (2011), 'A Systematic Approach to Performance Drilling in Hard Rock Environments'. Paper Presented at the SPE/IADC Drilling Conference and Exhibition (SPE/IADC 139841), Amsterdam, The Netherlands.

Elsborg, C., Carter, J. and Cox, R. (1996), 'High Penetration Rate Drilling with Coiled Tubing'. Paper Presented at the SPE International Conference on Horizontal Well Technology (SPE 37074), Calgary, Canada.

Eren, T. (2010) Real-Time-Optimization of Drilling Parameters During Drilling Operations, School of Natural And Applied Sciences, Middle East Technical University, Thesis, Doctor of Philosophy.

Eskin, M. and Maurer, W.C. (1997) Advanced Downhole Drilling Motors, Maurer Engineering Inc.

Fletcher, T. (1992) 'Drilling Exploration Boreholes beyond 4000m in South Africa', Mine Water and The Environment, Vol. 11(No. 4).

Franca, L.F.P. and Lamine, E. (2010), 'Cutting Action of Impregnated Diamond Segments: Modelling and Experimental Validation'. Paper Presented at the The 44th U.S. Rock Mechanics Symposium and 5th U.S.-Canada Rock Mechanics Symposium (ARMA 10-439), Salt Lake City, UT, USA.

Fuchs, K., et al. (1990) 'Super-Deep Continental Drilling and Deep Geophysical Sounding', Springer Verlag.

Galbierz, B.E. and Oglesby, K.D. (2005) Advanced Mud System for Microhole Coiled Tubing Drilling, Final Report, U.S. Department of Energy, Bandera Petroleum Exploration LLC, Impact Technologies LLC.

Gantt, L.L., Erin, M.O. and Leising, L. (1998) 'Coiled Tubing Drilling on the Alaskan North Slope', Oilfield Review.

Gaynor, T.M. (1988) 'Downhole Control of Deviation with Steerable Straight-Hole Turbodrills', SPE Drilling Engineering.

Georgi, D.T., Harville, D.G. and Robertson, H.A. (1993), 'Advances in Cuttings Collection and Analysis'. Paper Presented at the SPWLA 34th Annual Logging Symposium.

Grigor, C., Conroy, D. and Henderson, M. (2008), 'Expanding the Use of Turbodrills in Coiled Tubing and Workover Applications'. Paper Presented at the SPE/ICoTA Coiled Tubing and Well Intervention Conference and Exhibition (SPE 113721), The Woodlands, Texas, USA.

ICoTA (2005) An introduction to Coiled tubing: History, Applications, and Benefits, (The Intervention \& Coiled Tubing Association). http://www.icota.com.

IT (2007) Advanced Ultra-High Speed Motor for Drilling, (Impact Technologies LLC). Tulsa, Oklahoma, Final Report, US Department of Energy, National Energy Technology Laboratory (NETL).

Judzis, A., et al. (2006), 'Investigation of Smaller-Footprint Drilling System; Ultrahigh-Rotary-Speed Diamond Drilling Has Potential for Reduced Energy Requirements'. Paper Presented at the IADC/SPE Drilling Conference (IADC/SPE 99020), Miami, Florida, U.S.A.

Langille, P., Deen, A. and Klassen, J. (2009), 'Minimizing Risks, Maximizing On-Bottom Drilling Time: Turbodrilling with Impregnated Bits Improve Efficiency and Circumvents Trouble Time, Southern Oklahoma'. Paper Presented at the SPE/IADC Drilling Conference and Exhibition (SPE/IADC 119230), Amsterdam, The Netherlands.

Lyons, W.C. and Plisga, G.J. (2005) Standard Handbook of Petroleum \& Natural Gas Engineering, United States of America, Elsevier Inc.

Maehs, J., Law, A. and Pruitt, R. (2005), 'Drilling With Success: BHA Optimization for Coiled-Tubing Drilling in Harsh Environment'. Paper Presented at the SPE/ICoTA Coiled Tubing Conference and Exhibition (SPE 94162), The Woodlands, Texas, U.S.A.

Maranuk, C.A., et al. (2000), 'A Concept of a New Steerable Drilling System for Coiled Tubing'. Paper Presented at the SPE/ICoTA Coiled Tubing Roundtable (SPE 60752), Houston, USA.

Marjoribanks, R. (2010) Geological Methods in Mineral Exploration and Mining, Berlin Heidelberg, Springer-Verlag.

Maurer-Engineering-Inc. (2000) Advanced Geothermal Turbodrill, Final Report. Houston, TX, U.S. Department of Energy.

Maurer, W.C., et al. (1977) Downhole Drilling Motors: Technical Review. Houston, Texas, Maurer Engineering Inc.

MEDC (Modeling Engineering \& Development Company Limited), Fatigue Analysis for Coiled Tubing, User Manual, www.medcotas.com.

Mokaramian, A., Rasouli, V. and Cavanough, G. (2012), 'Adapting oil and gas downhole motors for deep mineral exploration drilling' in Deep Mining 2012: Proceedings of the sixth International Seminar on Deep and High Stress Mining, Australian Centre for Geomechanics (ACG), Perth, Western Australia, pp. 475-486. 
Mushovic, T., et al. (2009), 'Beyond the Technical Limit: Turbodrilling-A Paradigm Shift to World Class Horizontal Well Construction'. Paper Presented at the SPE/IADC Drilling Conference and Exhibition (SPE/IADC 118809), Amsterdam, The Netherlands.

Natanael, M., et al. (2006) Methods for making a turbodrill, US patent. U.S.A., Smith International, Inc.

Natanael, M., et al. (2008) Turbodrill with asymetric stator and rotor vanes, US Patent U.S.A, Smith International, Inc.

NETL (2005) Coiled Tubing: State of the Industry and Role for NETL, (National Energy Technology Laboratory) U.S. Deparment of Energy.

Newman, K., Kelleher, P. and Smalley, E. (2007) Friction Reduction for Microhole CT Drilling, Final Technical Report, CTES, L.P. , U.S. Department of Energy.

Noynaert, S., Pumphrey, D. and Pink, T. (2007), 'Drilling for Coalbed Methane in the San Juan Basin with Coiled Tubing: Results, Learnings, and a World First'. Paper Presented at the SPE/IADC Drilling Conference (SPE 105874), Amsterdam, The Netherlands.

Pierce, K.G., Livesay, B.J. and Finger, J.T. (1996) Advanced Drilling Systems Study, SAND95-033, U.S. Department of Energy (DOE).

Portman, L. (2000), 'Reducing the Risk, Complexity and Cost of Coiled Tubing Drilling'. Paper Presented at the IADC/SPE Asia Pacific Drilling Technology (IADC/SPE 62744), Kuala Lumpur, Malaysia.

Precision-Energy-Services (2000) Directional Drilling 1, Operational Manual.

Qui, W., Miska, S. and Volk, L. (May 1998) 'Analysis of Drill pipe/Coiled-Tubing Buckling in a Constant Curvature Wellbore', Journal or Petroleum Technology.

Rabia, H. (1985) Oilwell drilling engineering: principles and practice, Graham \& Trotman.

Rabia, H. (1985) 'A Unified Prediction Model for Percussive and Rotary Drilling', Mining Science and Technology, Vol. 2.

Radtke, R., et al. (2011) High-Power Turbodrill And Drill Bit For Drilling With Coiled Tubing, Technology International, Inc., US Department of Energy, National Energy Technology Laboratory (NETL).

Regener, T., et al. (2005), 'Latest Positive Displacement Motor and Drill Bit Developments for Drilling Hard and Abrasive Formations'. Paper Presented at the SPE/IADC Drilling Conference (SPE/IADC 92542), Amsterdam, The Netherlands.

Reich, M., et al. (2000), 'Competitive Performance Drilling with High-Speed Downhole Motors in Hard and Abrasive Formations'. Paper Presented at the IADC/SPE Drilling Conference (IADC/SPE 59215), New Orleans, Louisiana.

RIO (2004) Current Capabilities of Hydraulic Motors, Air/Nitrogen Motors, and Electric Downhole Motors, (RIO Technical Services). Final Report, US Department of Energy.

Sanchez, A., Samuel, G.R. and Johnson, P. (1996), 'An Approach for the Selection and Design of Slim Downhole Motors for Coiled Tubing Drilling'. Paper Presented at the SPE Horizontal Drilling Conference (SPE 37054), Calgary, Canada.

Schlumberger (2010) Smaller Footprint Drilling System for Deep and Hard Rock Environments; Feasibility of UltraHigh-Speed Diamond Drilling, (Terra Tek). Salt Lake City, UT, USA, Final Edition, US Department of Energy (DOE), National Energy Technology Laboratory (NETL).

Seale, R., Beaton, T. and Flint, G. (2004), 'Optimizing Turbodrill Designs for Coiled Tubing Applications'. Paper Presented at the SPE Eastern Regional Meeting (SPE 91453), Charleston, West Virginia, U.S.A., .

Seale, R. and Conroy, D. (2005), 'PDC Bits Run on Turbodrills: The History, Facts and Current Developments'. Paper Presented at the SPE Latin American and Caribbean Petroleum Engineering Conference (SPE 94826), Rio de Janeiro, Brazil.

Staley, C., et al. (2011), 'Turbodrill BHA Solves Build Section Challenges, Anadarko Basin'. Paper Presented at the SPE/IADC Drilling Conference and Exhibition (SPE/IADC 140245), Amsterdam, The Netherlands.

Theimer, K. and Kollé, J. (2007) Microhole High-Pressure Jet Drill For Coiled Tubing, Final Report, Tempress Technologies Inc., US Department of Energy (DOE).

Turner, D.R., et al. (1999), 'Electric Coiled Tubing Drilling: A Smarter CT Drilling System'. Paper Presented at the SPE/IADC Drilling Conference (SPE/IADC 52791), Amsterdam, Holland.

Turner, D.R., et al. (1999), 'The All Electric BHA: Recent Developments toward an Intelligent Coiled-Tubing Drilling System'. Paper Presented at the SPE/ICoTA Coiled Tubing Roundtable (SPE 54469), Houston, Texas, U.S.A.

Walker, S.H. and Millheim, K.K. (1990) 'An Innovative Approach to Exploration and Exploitation Drilling: The SlimHole High-Speed Drilling System', Journal of Petroleum Technology.

Williams, T. and Deskins, G. (2001) Sound Coiled-Tubing Drilling Practices, Maurer Technology Inc., U.S. Department of Energy. 